\title{
INVESTIGACIÓN/RESEARCH
}

\section{CONSTRUCCIÓN DEL ESPACIO NARRATIVO EN EL CINE DE JOHN MCTIERNAN: HACIA EL SELLO DE AUTOR}

José Rodríguez Terceño1: Universidad Complutense de Madrid. España. josechavalet@gmail.com

\section{RESUMEN}

La línea de investigación del concepto de estilema de autor o sello autorial centra el objeto principal del presente artículo en el que se pretende desgranar los mecanismos narrativos, en cuanto a historia y discurso, empleados por el director John McTiernan, adscrito al cine comercial hollywoodiense, para construir el espacio hodológico de sus filmes (dentro del género de acción, también de factura estadounidense). Se pretende pues profundizar en uno de los aspectos capitales, pero no único, en lo que a definición de áreas de estilema podemos considerar hoy como investigaciones punteras.

PALABRAS CLAVE: McTiernan - Sello de autor - Espacio Narrativo - Hodológico Historia - Discurso

\section{CONSTRUCTION OF NARRATIVE SPACE IN JOHN MCTIERNAN'S FILMS: TO AUTHOR'S SIGNATURE}

\section{ABSTRACT}

The research line author's styleme concept copyright or authorial signature centers the main focus of this article which is to shell the narrative mechanisms, in terms of history and discourse employed by director John McTiernan attached to the Hollywood commercial cinema to build the space of his films (within the action genre, also American bill). As it aims to deepen one of the major issues, but not unique, as far as defining areas of styleme we consider today as cutting-edge research.

\footnotetext{
${ }^{1}$ Autor correspondiente:

José Rodríguez Terceño: Doctorando en la Facultad de Ciencias de la Información de la Universidad Complutense de Madrid. España.

Correo: josechavalet@gmail.com
} 
KEYWORDS: McTiernan - Author's signature - Narrative space - History - Discourse

\section{INTRODUCCIÓN}

El campo del sello de autor en su modalidad cinematográfica es un terreno abonado para la investigación científica desde que la hoy famosa política de los autores francesa alcanzará su éxito en las décadas de los años sesenta y setenta del siglo pasado. Pero a diferencia de las directrices popularizadas por los cuadernos de cine franceses, carentes de toda racionalidad teórico-científica, nuestro análisis posee una fuerte componente analítico-textual que nos va a permitir extraer los mecanismos seleccionados por el director neoyorquino John McTiernan a la hora de construir sus espacio narrativos hasta hacer de ellos un estilema característico de su sello autorial.

El reto es mayor si consideramos que grandes autores han hollado ya este nuestro camino -no solo en lo que a sello de autor se refiere, también dentro de la perspectiva audiovisual-; una línea de investigación que iniciaran nombres tan respetados como Jesús García Jiménez, Francisco García García, Estanislao Ramón Trives, Jesús González Requena, David Caldevilla Domínguez o Juan Enrique Gonzálvez Vallés, entre otros. Nos encontramos en una situación creadora en el plano audiovisual cinematográfico ya estudiado por numerosos autores y desde las más variadas ópticas y enfoques.

El concepto de estilema de autor, ya enunciado por García Jiménez, hace referencia a una marca personal, fácilmente identificable, intransferible pero si imitable. Es decir, una forma de hacer en lo que a forma y contenido se refiere de una persona en relación con un arte determinado. La variedad de enfoques que podemos encontrar en nuestro camino investigador nos proporciona un concepto holístico que conforma un espacio hodológico característico de la individualización textual, de un autor dentro del conjunto de obras existentes.

David Caldevilla, cuyos estudios han concretado mejor que ningún otro el sello de autor cinematográfico, señala la importancia de la selección, agrupación, dosificación y emisión de los contenidos, así como su manera o modo, determinante para el texto, ya que puede marcar todo el sentido de la narración o historia (Caldevilla, 2005). En otras palabras, "el suyo específico del cine hay que buscarlo no en la historia, sino en el discurso tal y como hemos visto ya, por lo que no es aventurado afirmar que «en el cómo, vemos qué se cuenta»"(Caldevilla, 2005, p. 11).

Lingüística y semiótica se interrelacionan en el cine para construir el relato cinematográfico, en el sentido de que existen dos niveles en los que se desenvuelve todo relato, uno lingüístico -temático o de argumento-, y otro retórico -semiótico o metalingüístico-. Esa relación, o por mejor decir, la forma en que será tratada por cada autor posibilitará la creación de obras con su particular sello de autor personal que dependerán de diversos aspectos que van desde la forma de entender el cine y el relato hasta el denominado «diccionario cultural personal» de cada uno de nosotros. 
Por lo tanto todo autor creará su estilema personal siguiendo las reglas que él considera acertadas, entendiendo de una forma singular el lenguaje cinematográfico y sus conformantes (en los ámbitos de forma y de temática), aplicando de la forma que él considera correcta todos los elementos que conforman el discurso narrativo. En este momento hablaremos de códigos narrativos propios basándonos en los ya preexistentes (efecto género) o creando exnovo nuevas fórmulas (Caldevilla, Terceño y Gonzálvez, 2012, p. 317).

Nuestro objetivo es focalizar el esfuerzo en la construcción del espacio hodológico por parte de John McTiernan hasta comprobar lo determinante que es en relación con su obra y con su sello de autor.

\section{METODOLÓGIA}

Partiendo de una componente analítico-textual, seguiremos el ya clásico esquema que desarrollara Seymour Chatman (1990) y que citamos a continuación, que nos permite definir el camino a seguir por toda creación artística, susceptible pues del análisis más exhaustivo y pertinente. Posibilita igualmente la opción de enumerar todos los constituyentes del sello autorial, en otras palabras, es la llave para completar nuestro pretendido sello en futuros trabajos.

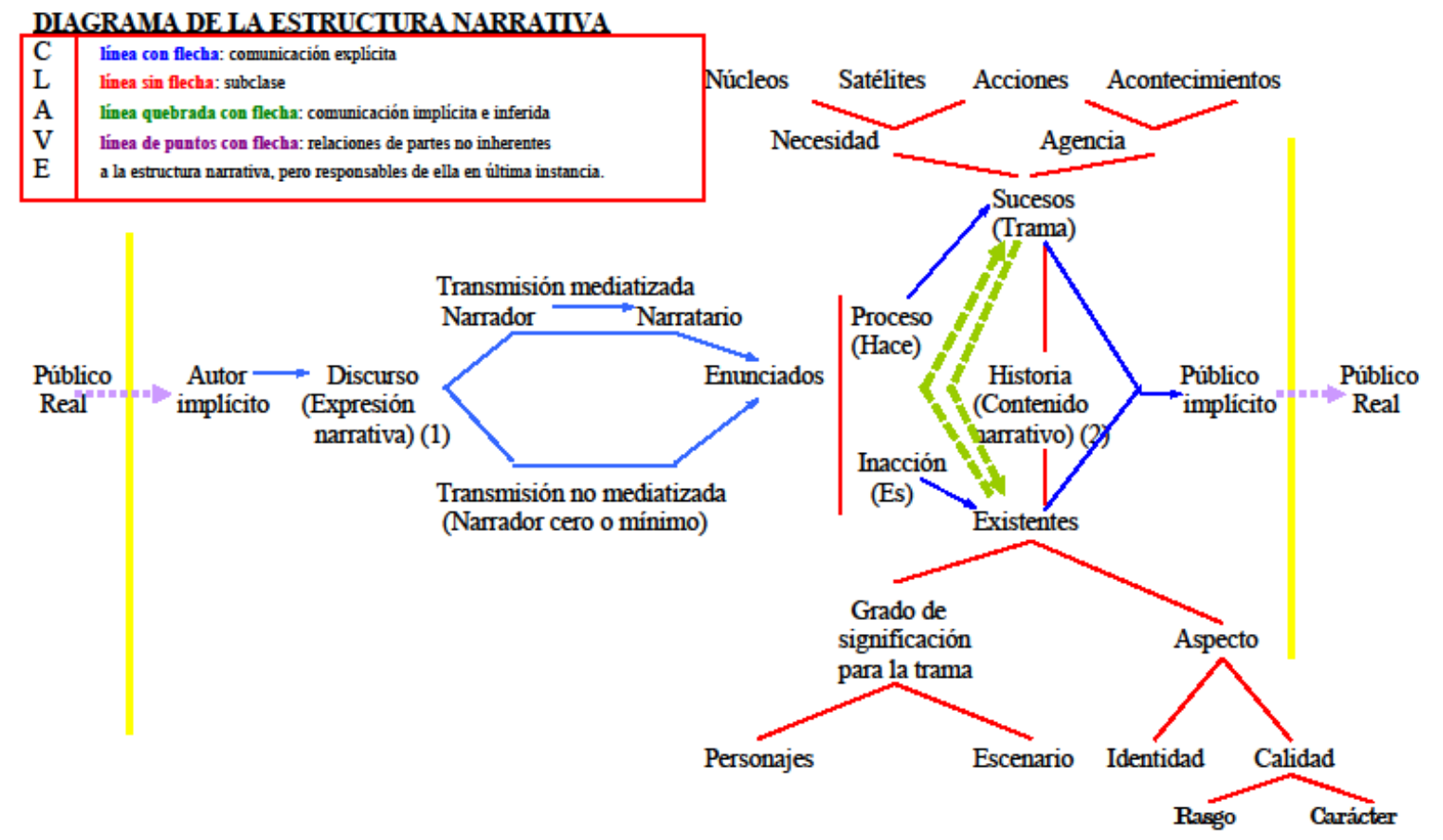

(1) Ésta es la forma de la expresión narrativa; su sustancia o manifestación aparece en varios medios (Verbales. novela, historia; Visuales: cuadros, tebeos; Audiovisuales: cine, televisión...) (2) Ésta es la forma del contenido, no la sustancia.

El sello de autor se ha de mostrar en todos los elementos narratológicos mostrados por el esquema de Chatman, aunque nosotros nos centraremos en uno solamente, el escenario o el espacio. Analizar la construcción del espacio hodológico en el cine de McTiernan será esclarecedor para comprender lo que el estudio del estilema de autor 
puede depararnos en futuras investigaciones, como puede ser la de completar el sello de autor, analizando todos los aspectos del esquema, en nuestro director elegido.

A partir de aquí nos detendremos en los existentes, en el espacio o escenario, pero sin olvidar la importancia que tienen el resto de los agentes de la historia, sucesos acciones y acontecimientos-, personajes, temáticas, ideologías, referentes, etcétera; o, en el plano del discurso, la estructura de la transmisión narrativa cinematográfica (audiovisual), así como su manifestación (elementos de naturaleza sonora y visual). Apliquemos pues esta metodología al caso concreto del espacio narrativo en el cine de John McTiernan.

\section{CONSTRUCCIÓN DEL ESPACIO NARRATIVO EN EL CINE DE MCTIERNAN}

El dominio del espacio y del escenario de la acción es una pieza fundamental en el cine comercial caracterizado por su espectacularidad en las imágenes. Requiere del buen saber hacer por parte del director para que el público no se desoriente durante la acción. En este saber hacer se han de reunir las cualidades propias de todo autor cinematográfico, a saber, planificación, movimientos de cámara, movimientos de los actores, montaje, etcétera, y todo ello perfectamente coordinado. Los avances tecnológicos posibilitan hoy día, además de un ahorro económico importante, la realización digital de estos escenarios destinados a la acción simplificando su rodaje. A ello hemos de sumarle la cada vez mayor influencia de otras formas de consumo inherentes al público joven ( $\mathrm{y}$ no tan joven) como son los videos musicales $\mathrm{y}$, muy especialmente, los videojuegos. Dejando de lado que éstos impongan dinámicas de breve esfuerzo -por no decir nulo o inexistente- e inmediata recompensa, y condenando a sus usuarios a no tolerar el esfuerzo a medio o largo plazo para la obtención de primas $y$, lo que es peor, no saber responder a la frustración, el abigarramiento en sus planos y el montaje yuxtapuesto de breves imágenes está contagiando al cine de unas películas con escenas de acción donde prima la espectacularidad por encima de todo hasta llegar al extremo de que poco importa tener percepción de lo que está pasando, cómo está pasando y dónde está pasando en la pantalla. Contribuyen también una reducción en todas las escalas del lenguaje cinematográfico, es decir, el abuso de planos muy cortos combinados con planos abiertos pero sin pasos intermedios de contextualización y la menor duración de los mismos, de apenas fracciones de segundo en los casos más exagerados, obligando a un montaje excesivamente rápido que ocasiona la completa desorientación del espectador. Lo que pretendemos demostrar a continuación es que John McTiernan es sabedor de la necesidad orientativa del público ante la narración y muy especialmente en las películas de acción o en las escenas de acción. Pero para llegar a ello refirámonos previamente al espacio como existente de la narración.

En primer lugar, podemos y debemos distinguir entre el espacio de la historia y el espacio del discurso (Chatman, 1990), entre el espacio como elemento formal de la narración y el espacio como categoría del discurso, en el sentido de concepto ordenador del mismo. 
Dentro de la narración, dentro de la historia -el 'qué'- podemos distinguir entre el espacio explícito y el espacio implícito. El primero hace referencia al espacio que es mostrado en pantalla en un momento dado, en otras palabras, es visible y aparece -la focalización como específica y exclusiva del discurso narrativo audiovisual a partir de 'puntos de vista' y 'restricción de campos' donde se localiza el sello de autoría que precisa de este tipo de elementos para poder tomar carta de naturaleza dentro del ámbito narrativo (Genette); mientras que el segundo es el espacio que para el espectador queda fuera de la pantalla pero visible para los personajes, es decir, el contra-tipo del espacio fuera de campo y las infinitas cavidades que aportan los significantes del lenguaje audiovisual.

El espacio como elemento formal, espacio audio-visual, se desata en los espacio escénicos, de los de la fotografía o la pintura, cuando cambia de plano en el interior mismo del espacio.

Las propiedades del espacio son: libertad focalizadora -opción de escoger lo que se ve o no se ve en pantalla-, importante en lo tocante al sello autorial de McTiernan, fragmentación espacial y profundidad; ayudando además a crear situaciones, matizándolas y marcándolas en su génesis debido a su carácter o constitución. Como afirma Francisco García García (1991, p. 673), el espacio "influye en la acción oponiendo resistencias a las intenciones de los personajes".

El espacio del relato audiovisual también se va a definir por una serie de características, como son:

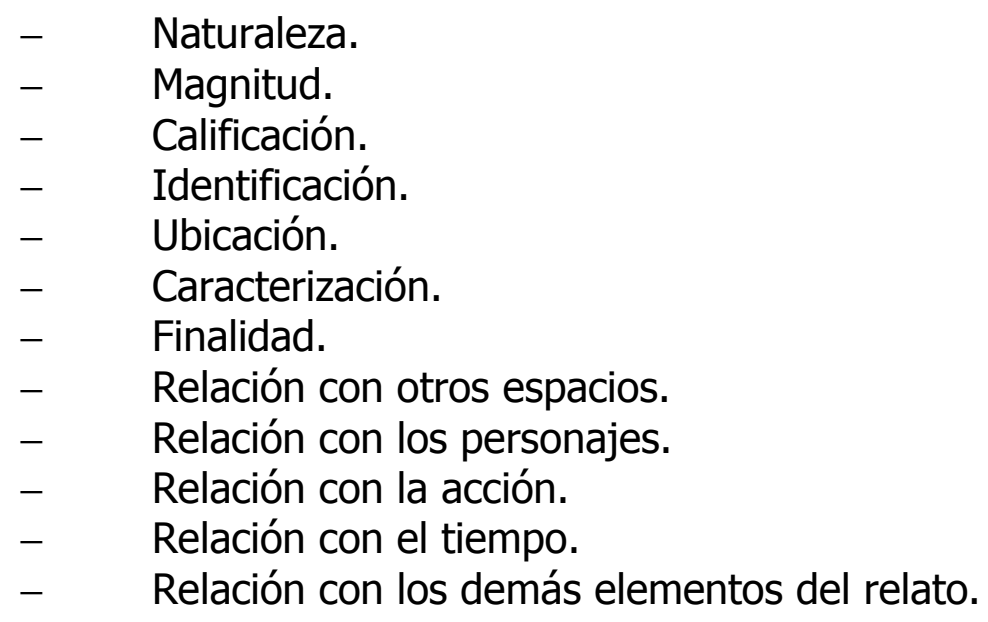

Como afirma Jesús García Jiménez, el espacio es una categoría ordenadora de la acción. "No es posible la percepción de la imagen discursiva, tal como interviene en el hecho narrativo, sin una referencia espacial: la diégesis pasa necesariamente por la mímesis y la imagen narrativa por la percepción del mundo natural"(García Jiménez, 1993, p. 351). Esta condición hace que en todo relato aparezcan: espacios realistas, espacios cualificantes, espacios ordenadores, espacios simbólicos, espacios interiores, espacios reguladores, espacios íntimos, personales, sociales y públicos, espacios intelectuales, morales, políticos e ideológicos, espacios mágicos, espacios homogéneos y espacios sintéticos, espacios referenciales, culturales y espacios imaginarios. 
El lenguaje audiovisual construye textos verbo-icónicos cuyos significados son espacios simbólicos e interiores que luchan, confirman, rectifican, modalizan o transforman el espacio físico y visible. También encontramos un espacio que regula los vínculos entre las funciones narrativas, el espacio como categoría formal del discurso, imprescindible para el entendimiento del espectador pues permite construir mensajes que lo facilitan.

Así, en el discurso narrativo distinguimos entre:

- Espacio hodológico: opuesto al matemático y al abstracto para que pueda transportar el significado de la percepción espacial a ámbitos de la abstracción y simbolización, originando espacios psicológicos, sociales, ideológicos, intelectuales y morales que permiten el análisis semiológico entre enunciación y elementos estructurales del relato.

- Espacio homogéneo: intercambiables, esquemáticos, sometidos a la necesidad mecánica, a la causalidad y a la discontinuidad.

- Espacio sintético: configurados por múltiplex (como en televisión por ejemplo).

- $\quad$ Espacio temporalizado: son tiempos espacializados.

El espacio es el verdadero hilo conductor de los encuentros y desencuentros del hombre frente al hombre, que es la base de todo drama -el espacio y el tiempo son las dos categorías de la apriorística de Kant según la cual, el sujeto ante un objeto cercano añade un tiempo y un espacio elaborados como constructos de su mente, para facilitar la comprensión por parte del sujeto-.

Aplicados estos pensamientos a la filmografía de John McTiernan vemos que nuestro director construye el espacio explícito con todos los detalles necesarios para la matización de los mismos creando espacios hodológicos claustrofóbicos (la densidad de la jungla, el reducido espacio de los submarinos, etcétera), a la par que hostiles, agresivos, violentos, e intempestivos y únicos.

En el relato visual el espacio es concreto, literal y taxativo (esto es, uno y el mismo para todos); es un percepto. El espacio hodológico claustrofóbico y hostil creado por McTiernan responde a un espacio (o espacios) único elegido estratégicamente como el mejor.

El espacio como signo, tiene un valor conectivo o deíctico, en la medida en que remite a una instancia de la enunciación, y determina que, en lo tocante al autor, su naturaleza y su uso lo convierten en un verdadero estilema (García Jiménez, 1993). Es decir, en esos espacios creados, resaltados con el fenómeno de la focalización, es donde reside una parte del estilo autorial de John McTiernan. 
El sentido del espacio cinematográfico es esencial en la relación que el autor y el espectador establecen para con la historia, y más concretamente entre el público y su orientación (literal) en el relato. Algunos elementos del lenguaje fílmico destacan por encima de otros a la hora de construir el espacio y facilitar el posicionamientos del espectador, entre ellos la planificación, los movimientos de cámara, los movimientos actorales, la profundidad de campo y el montaje. Estos dos últimos elementos permiten una construcción del espacio mediante tres características del discurso: fragmentación, yuxtaposición y sucesión. El buen uso de la profundidad de campo y del montaje posibilitan que el espectador no perciba estos rasgos sino que tenga la impresión de un espacio unitario.

John McTiernan tiene predilección por los escenarios únicos, entiéndase la casa de Pommier en "Nómadas", la jungla en "Depredador", el rascacielos en "Jungla de cristal", el submarino en "La caza del Octubre Rojo", la jungla nuevamente en "Los últimos días del Edén", el poblado vikingo en "El guerrero número 13", la pista de juego en "RollerbalI" y la base militar (comedor, enfermería y despacho, principalmente) en "Basic". De esta forma puede centrar su potencial en la puesta en escena, los movimientos de cámara y tener claro desde el principio el montaje final de la secuencia o del filme completo. Mct suele introducirnos en los espacios y los escenarios de la mano de alguno de los personajes, ya sea desde una cámara subjetiva, donde vemos a través de la mirada, de los ojos, del personaje, como ocurre en la primera incursión en la que será la futura casa de Jean Charles Pommier y señora, donde vamos recorriendo las estancias viéndolas, al tiempo que la doctora Flax, a través de la mirada del antropólogo - "Nómadas". o bien siguiendo a uno de los personajes mientras se pasea por el escenario, donde el movimiento de la cámara es absoluto, utilizando la técnica que se denomina «tracking shot», es decir, plano de seguimiento. La cámara, siempre activa, sigue de cerca al personaje pero sin pegarse a él hasta confundirse con un plano subjetivo o semi-subjetivo. Hay una distancia prudencial entre la cámara y el personaje destinada a facilitar el reconocimiento del espacio por parte del espectador, lo que le permite orientarse y sentirse al mismo tiempo cómodo, facilitando la lectura y legibilidad de las escenas de acción posteriores donde el montaje se caracteriza por planos más cortos y más breves. En el caso de "Jungla de cristal", donde la cámara sigue a varios personajes por algunos de los escenarios de los diversos pisos que aparecen en el filme, este tipo de movimiento de cámara y exposición del espacio permite al público familiarizarse tanto con el espacio que refuerza la empatía que posteriormente le relaciona con el héroe al uso que será McClane. Conocer el espacio al tiempo que lo hace el protagonista y desenvolverse con él por un terreno no del todo desconocido, fomenta la proyección e identificación con la figura heroica.

El espacio en el cine de John McTiernan, como los demás rasgos que estamos viendo y que veremos en las páginas posteriores, se caracteriza la búsqueda de cierta musicalidad, de cierto fluir suave y agradable - "Jungla de cristal"- o su opuesto, fuertes sacudidas de la cámara, ruptura de la continuidad y cortes abruptos - "Jungla de cristal. La venganza". 
McTiernan - Sello de autor - Espacio Narrativo - Hodológico - Historia - Discurso

Hay una tradición narrativa que conecta el cine con la literatura, como en el inicio de "La flauta mágica" de Bergman (1975) en donde los planos están montados como si se estuvieran pasando las hojas de un libro. Este enfoque no me ha dicho nunca nada'(John McTiernan en Cahiers du cinéma, número 690, junio. París, 2013. P. 92).

McTiernan tiene muy claro que existen ciertas necesidades espaciales cuando se trabaja en un filme, de mayor exigencia cuando se trata de un filme de acción:

Existe una regla estricta para todo filme de acción: debes tener una legibilidad perfecta del espacio y comprender la geografía de la película. Debes tener la impresión física de estar allí. El lugar es el centro del problema. Sin relación con el lugar no se comprende la historia. La vida es una serie de acciones: si ves a alguien corriendo sin saber dónde está, no dónde va, no comprendes nada-sin necesidad de agitar planos con gran foco para dar la sensación de urgencia y realismo-. El público comprende una sola cosa a la vez. Si quieres tener el control de un instrumento, como un piano, debes saber de antemano la secuencia de los pensamientos del espectador, en qué orden van las cosas, la forma en que debe recibir la información: es decisivo para el suspense. Las informaciones de un filme no funcionan como 'acceso aleatorio', como en muchas tecnologías actuales. Es una de las razones por las que adoro "La noche americana" de Truffaut, porque es tan simple, recta y honesta en su progreso, y trabaja siguiendo esa lógica, una sola cosa por vez'(John McTiernan en Cahiers du cinéma, número 690, p. 92. El subrayado es nuestro).

Para lograr una mayor participación del espacio McTiernan recurre al constante movimiento de cámara porque "el movimiento amplifica la sensación de espacio, permite aprehender las tres dimensiones de un lugar, jugar con los registros de las distancias o la posición estratégica que relaciona un personaje con otro" (en Cahiers du cinéma, número 690, ibídem). Todo ello no lo lograría si no concibiera sus filmes en su mente antes de emprender cualquier acción, y éstas siempre persiguen el mejor de los resultados utilizando las técnicas más sencillas (al tiempo que ahorra costes de producción y puede emplearlos en lo esencial dentro de la película). En una entrevista concedida recientemente a los cuadernos de cine franceses (número 690, p. 89) descubre su gran secreto para visualizar el espacio de la acción de sus obras:

El cineasta prepara todas sus películas aquí, gracias a un antiguo programa informático de arquitectura que le permite modelar sus decorados, concebir el espacio y las construcciones necesarias para la elaboración de una secuencia con un efecto dinámico. De la arena de "Rollerball" a un esquema técnico de una bomba de "Jungla de cristal. La venganza", de la gruta de los Wendol de "EI guerrero número 13" a una secuencia de una batalla en la China medieval en un escenario de «buques propulsados gracias a caballos galopando en ruedas gigantes» (para la adaptación abortada de las aventuras del Juez Ti de Robert Van Gulik), la obra real o el imaginario de un autor desfilando ante nuestros ojos.

El propio McTiernan completa la impresión del periodista: 
McTiernan - Sello de autor - Espacio Narrativo - Hodológico - Historia - Discurso

Realizar un filme es técnica y es ciencia. Puedes preverlo todo bien, hacer todo lo posible para que funcione, pero la cámara no tiene perdón ni piedad: puedes pasarte el día entero hasta tener planificado el noventa y nueve por ciento que un pequeño detalle puede derrumbarlo y echar todo a perder (John McTiernan en Cahiers du cinéma, número 690, p. 90).

Por otra parte, existe también la idea de espacio psicológico, en la que una acción se muestra de un modo significativo a nivel psicológico, que es reforzada con formas focalizadoras que subrayan una misma idea. Un esfuerzo que se hace patente en su composición del espacio, tanto como en la puesta en escena, movimientos de cámara y órdenes actorales, y en la caracterización de los mismos mediante la iluminación o la música, haciendo que los escenarios se construyan a partir de los personajes y los sucesos (acciones y acontecimientos), haciendo, finalmente, que trasciendan en la creación de ambientes y atmósferas. Ello le permite que incluso en escenarios abierto la sensación de claustrofobia sea patente para los personajes al mismo tiempo que lo es para el espectador, como demuestran la densidad selvática en "Depredador"o la bruma indistinguible del cielo gris y nuboso en "El guerrero número 13"y que no deja ver mucho más allá de unos cuantos metros, haciendo que la atmósfera hostil se intensifique, como la negrura que rodea el escenario donde se desarrolla la acción que viven los protagonistas de "Basic", los terribles sucesos acontecidos durante las maniobras en las que han sido desplegados.

El escenario descrito de "Basic" da una idea de irrealidad característica de las mentiras y medias verdades que tiene que resolver la protagonista. El ataque de los Wendol al poblado vikingo en "El guerrero número 13"iluminado apenas por el fuego de las antorchas y las casas quemadas subraya su carácter onírico hasta que el protagonista, Ibn Fadlan, toma contacto con la realidad, resaltando entonces el brillo rojo de la batalla. Es un buen ejemplo de la iluminación al servicio de la atmósfera espacial. O los tres diferentes submarinos entre los que se desarrolla la intriga de "La caza del Octubre Rojo"y que funcionan como trasuntos de las circunstancias físicas y psicológicas de los personajes; el puesto de mando del submarino nuclear $\mathrm{V}$. K. Konovalov, capitaneado por Tupolev, oscurecido y a medio iluminar en todo momento (a diferencia de las otras dos naves) y con los cilindros metálicos del periscopio ocupando gran parte de su espacio, refleja la mentalidad de su retorcido líder.

El adecuado uso de los elementos intervinientes en la construcción del espacio, como ya hemos señalado, ayudan a que el espectador se localice en el filme, a que tenga la sensación de estar en el lugar donde se desarrolla la acción, a que lea correctamente el espacio y comprenda la geografía de la película y, sobre todo, a que se identifique en cada momento con el personaje protagonista. Es sin duda alguna una marca característica del buen hacer de McTiernan y un garante de su éxito.

También, y en relación con la planificación, la puesta en escena y los movimientos de cámara, y el hecho de que McTiernan, siempre que las condiciones de producción cuando no los propios productores- se lo permiten, rueda en formatos panorámicos y en anamorfico (a excepción de sus dos primeros filmes, más 'cuadrados', rueda 
siempre en una relación de aspecto de 2.35:1) -nos ocuparemos de ello más adelante-, algo que se puede observar perfectamente en sus exteriores abiertos, es común en nuestro director utilizar el zum óptico bien para focalizar algún punto concreto dentro del espacio o bien como un movimientos de aproximación hacía el escenario, como si se 'empujara' al espectador hacía él, como si, permítasenos compararlo, intentará procurar una suerte de inmersión en el escenario por parte del espectador. También utiliza el movimiento de forma invertida, aunque son las menos, de un punto concreto aleja la cámara y permite observar más espacio y facilitar la orientación del público. Por lo tanto, cuando ha de resaltar la importancia del espacio, ya sea de alguno de sus focos o bien sumergiendo al espectador en él, McTiernan utiliza las más de las veces el zum, anteponiendo esta técnica, que no distorsiona la imagen como haría el zum digital, a los movimientos de cámara, lo que subraya aún más la idea de rodar pensando en el montaje posterior, ya que la ausencia de complicados movimientos de cámara facilitan la presentación del espacio.

Esto no quiere decir que McTiernan no mueva la cámara, ya hemos señalado y lo volveremos a apuntar posteriormente que su cámara incansablemente activa es uno de sus rasgos particulares más y mejor definidos en su cine. Sencillamente queremos decir que en cuanto a la presentación del espacio en grandes planos abiertos, McTiernan opta por el plano fijo, moviendo la cámara con el zum en vez de orquestar diferentes puntos de tomas y los necesarios cortes y sucesión de planos encadenados.

No podemos finalizar este apartado sin dedicar unas breves anotaciones al espacio que es creado mediante la presencia de la banda sonora, de la música o de los sonidos existentes dentro del filme, ya sean diegéticos o extradiegéticos. El uso de los mismos va a permitir a McTiernan caracterizar sus imágenes visuales evocando al mismo tiempo las ya mencionadas atmósferas y ambientes, creando, en cierta forma, estados psicológicos ya se trate de dramatismo, suspense, humor, terror, etcétera.

Las concepciones de la música en el discurso narrativo audiovisual más comunes son: contextual, es decir, se necesita de ella para crear una atmósfera envolvente -la asfixiante sensación de claustrofobia que desprenden las imágenes de la densa jungla centroamericana en "Depredador" no sería posible sin la música de tensión y los ruidos característicos de estas zonas, amén de los planos que muestran la frondosidad del lugar o las copas de los árboles, dejando apenas espacio para la luz y dando cierta corporeidad al aire viciado y caliente que agobia a los personajes durante su recorrido. Parafrásica, la función tópica de la música en los filmes; diegética, evidentemente; dramática, que actúa sobre el universo de las emociones; y, finalmente, pragmática, característica de cualquier producción audiovisual.

La música -la banda sonora o banda de sonido por mejor decir- tiene, como señala Jesús García Jiménez, una función expresiva y una función referencial que sirve para ambientar la acción y por ende los espacios donde ésta tiene lugar. La música contribuye a la configuración del espacio narrativo mediante su función referencial, como hace el último movimiento de la Sinfonía número 9 de Beethoven en "Jungla 
de cristal", suficientemente típico, representativo y conocido por el espectador, tanto para imprimir carácter y divertimento al filme como para categorizar a los antagonistas como miembros de la coalición europea creciente como poder económico y político. También cumple una función focalizadora, pragmática, formante (que permite tener constancia de la atmósfera que remite directamente a cómo los personajes habitan el espacio, piénsese por ejemplo la música de Bill Conti para acompañar al personaje de Thomas Crown y los escenarios por los que se desenvuelve), expresiva, emotiva y ambiental (que responde a la creación perceptiva de un espacio en sus acepciones dramática y estética).

La música complementa lo que se muestra, y sugiere el espacio que la imagen no puede o no quiere representar, o bien recuerda la continuidad del espacio de la acción, segmentado a la vista por la planificación visual [...] La música es, entonces, un medio oportuno para «describir» este espacio que no oímos, y que sólo podemos ver intermitentemente. Mejor dicho, hay momentos en los que la música abre el encuadre, o al contrario, lo cierra de manera mucho más sutil e impalpable que lo que lo hacen los movimientos de cámara [...] Para una imagen (salvo que esté reconstruida en un decorado) no resulta tan fácil expresar el espacio abierto, mientras que la música dispone para ello de todo un código, heredado de la literatura sinfónica [...] La música hace eso mediante la continuidad de un único flujo, mientras que la imagen lo hace generalmente -en particular en la época del cine clásico-, mediante la discontinuidad de la imagen'(Chion, 1997, P: 224 y 225).

Estos usos de la banda de sonido, especialmente en lo que respecta a la creación de ambientes y atmósferas, situaciones emocional y descripción de acción o personajes, llega muy hondo en el inconsciente del espectador que se deja llevar por la espectacularidad de las acciones y el poder visual de la imagen, esto es, lo que se desarrolla ante sus ojos lo fascinan visualmente pero están muy marcadas y completadas en cuanto a significado por las imágenes técnicas sonoras en sus diversas variables, pero que sirven para ofrecer una idea general de su importancia, en tanto que constituye, como la imagen, un elemento hipnótico fundamental en el cine de McTiernan (como lo será la imagen y dentro de está la iluminación por ejemplo).

\section{CONCLUSIONES}

Entendemos por lo tanto que el estilema es una marca personal dibujada a través de la sustancia de la expresión y del contenido, observada por medio de la analítica textual con el objeto de sacar a la superficie las invarianzas fenomenológicas recurrentes en un autor y que estarán asociadas a él en toda su obra.

El recorrido llevada a cabo en la obra cinematográfica de John McTiernan ha demostrado la existencia de estas invarianzas en lo que a la construcción del espacio narrativo se refiere, hasta el punto de poder resumir nuestro planteamiento de la siguiente forma: John McTiernan recurre a la construcción de espacios hodológicos claustrofóbicos y hostiles en los que ordena su labor de dirección gracias al movimiento activo y constante de la cámara -plano de 
seguimiento de un personaje o el zum óptico en la presentación-, favoreciendo, de este modo, la amplificación de la sensación del espacio atmósferas y ambientes igualmente claustrofóbicos y hostiles-, la legibilidad del mismo y la comprensión geográfica del filme por parte del espectador.

Para poder elevar a categoría algunas de estas aseveraciones sería necesario completar el camino abierto gracias al presente trabajo, profundizando en el estudio de todos los aspectos que conforman el trabajo creativo autorial (audiovisualcinematográfico) que encontramos en el esquema citado al comienzo del presente elaborado por Chatman, conceptualizando finalmente el sello de autor de John McTiernan.

\section{BIBLIOGRAFÍA}

CALDEVILLA DOMÍNGUEZ, D. (2005). El sello de Spielberg. Madrid: Visión Net.

CALDEVILLA DOMÍNGUEZ, D., RODRÍGUEZ TERCEÑO, J \& GONZÁLVEZ VALLÉS, J. E. (2012). "El sello autorial en el cine clásico estadounidense contemporáneo". En PIÑEIRO OTERO, T. \& DEL VALLE DE VILLALBA, M. E. (2012). Nuevas tendencias en investigación sobre comunicación en el EEES. Madrid: Visión Libros.

CHATMAN, S. (1990). Historia y discurso. Madrid: Taurus.

CHION, M. (1997). La música en el cine. Barcelona: Editorial Paidós.

Entrevista a John McTiernan (2013) en Cahiers du cinéma, 690 (junio), 87-96. París.

GARCÍA GARCÍA, F. (1991). "El guión en los medios audiovisuales". En Diccionario de ciencias y técnicas de la comunicación. Madrid: Editorial Paulina.

GARCÍA JIMÉNEZ, J. (1993). Narrativa audiovisual. Madrid: Cátedra.

\section{José Rodríguez Terceño}

Licenciado en Comunicación Audiovisual por la Universidad Complutense de Madrid y doctorando en la rama de cine de la misma institución. Miembro del Grupo de Investigación Validado Complutense Concilium, ha participado en diversas publicaciones colectivas centradas en la séptima arte, periodismo y las relaciones públicas. 